VII JORNADAS DE DIFUSIÓN DE LA INVESTIGACIÓN Y EXTENSIÓN - FCV-UNL

RESUMEN EXTENDIDO

\title{
EVALUACIÓN DEL PERFIL DE VIRULENCIA DE Campylobacter TERMOTOLERANTES AISLADOS DE GRANJAS COMERCIALES DE POLLOS PARRILLEROS
}

\author{
Rossler $E^{1}$, Zimmermann J A ${ }^{1}$, Olivero $C^{1}$, Saluzzo $M^{1}$, Frizzo LS ${ }^{1,2}$, Zbrun M V ${ }^{1,2}$, \\ Sequeira $\mathrm{G} \mathrm{J}^{2}$, Antoniazzi $\mathrm{L}^{1}$, Signorini $\mathrm{M} \mathrm{L}^{2,3}$. \\ ${ }^{1}$ Laboratorio Análisis de Alimentos, Instituto de Ciencias Veterinarias del Litoral, Consejo Nacional de \\ Investigaciones Científicas y Técnicas (ICiVet-CONICET/UNL). \\ 2 Departamento de Salud Pública, Facultad de Ciencias Veterinarias, Universidad Nacional del Litoral \\ (UNL). \\ ${ }^{3}$ Consejo Nacional de Investigaciones Científicas y Técnicas, Instituto Nacional de Tecnología \\ Agropecuaria, EEA Rafaela (CONICET-INTA). \\ * Correspondencia: Rossler E. E-mail: eugerossler21@hotmail.com
}

Editado por: R. Sobrero, V. Matiller, C. Baravalle.

\section{VIRULENCE PROFILE EVALUATION OF THERMOTOLERANT CAMPYLOBACTER ISOLATES FROM COMMERCIAL BROILER FARMS.}

SUMMARY.

The aim of this work was to analyze the presence of genes associated with the virulence of thermotolerant Campylobacter (CT) isolated from different sources in commercial broiler farms. For this, we worked with a collection of CT isolates obtained from three commercial broiler farms during 2015. The presence of 10 genes related to CT virulence was examined with a PCR reaction. The results showed a prevalence of $100 \%$ for flaA and flhA; $91 \%$ cadF, $51 \%$ cdtABC, $48 \%$ iam, $46 \%$ racR, 32\% ciaB and $11 \%$ virB 11 . C. jejuni showed higher prevalence of all genes evaluated than C. coli, except iam and virB11 wich were higher for C. coli. The same gene pattern was presented in different sources of isolates. The high prevalence of flaA and flhA, involved in CT mobility, cadF related to Ca mpylobacter gut colonization of broiler and cdtABC genes involved for the expression of cytotoxin, indicates the importance of these factors in CT virulence. Differences in the prevalence of genes according to the species of CT could demonstrate different mechanisms of pathogenicity, and this is not related to the source of isolates. All the results showed the ability of CT to colonize cells but is not evidence of pathogenesis.

Palabras clave: Campylobacter termotolerante; pollos; granja; prevalencia; genes virulencia 
Campylobacter termotolerante (CT), principalmente Campylobacter jejuni y Campylobacter coli, es el principal agente zoonótico transmitido por alimentos causal de la campilobacteriosis humana. El tracto gastrointestinal del pollo es el principal reservorio de estos microorganismos. Durante el proceso de faena de los pollos, se produce la contaminación de la carne debido al método utilizado para la evisceración. Es así como Campylobacter se transmite al hombre a través del consumo de carne cruda, mal cocida o por contaminación cruzada de los alimentos (Silva et al. 2011). Los mecanismos moleculares implicados en la infección de CT en pollos podrían ser útiles para conocer características epidemiológicas de la enfermedad (Datta et al. 2003). Es así que se han descrito algunos genes cuya expresión estaría asociada con la virulencia de CT: flaA, flhA, cadF y racR (genes responsables de la adherencia y colonización de la mucosa intestinal) (Wieczorek \& Osek 2008, Josefsen et al. 2015); virB11, ciaB, iam (genes responsables de la invasión) (Wieczorek \& Osek 2008, Josefsen et al. 2015); $c d t A, c d t B$ y $c d t C$ (genes responsables de la producción de citotoxinas) (Wieczorek \& Osek 2008, Josefsen et al. 2015).

El objetivo de este trabajo fue analizar la presencia de genes asociados a la virulencia de CT aislados de diferentes fuentes en granjas comerciales de pollos parrilleros.

Para ello se trabajó con una colección de aislamientos de CT obtenidos en muestreos sucesivos en tres granjas comerciales de pollos parrilleros durante el año 2015 (C. jejuni $\mathrm{n}=80$ y C. coli $\mathrm{n}=60$ ). Los aislamientos fueron obtenidos a partir de muestras provenientes de: pollos parrilleros $(C$. jejuni $n=53$ y $C$. coli $n=51)$, aves silvestres (C. jejuni $\mathrm{n}=20$ y $C$. coli $\mathrm{n}=6)$, cascarudos $(C$. jejuni $\mathrm{n}=2$ y C. coli $\mathrm{n}=2$ ) y larvas (C. jejuni $\mathrm{n}=2$ ) de la cama (Alphitobious diaperinus), moscas (Musca domestica) (C. coli $\mathrm{n}=1$ ) y botas de los operarios de las granjas ( $C$. jejuni $\mathrm{n}=3$ ).

En todos los aislamientos se examinó la presencia de 10 genes relacionados con la virulencia de CT: flaA, flhA, $c a d F, \operatorname{racR}$, virB11, ciaB, iam, $c d t A, c d t B$ y $c d t C$. Para ello, en primer lugar, se realizó la extracción de $A D N$ genómico a partir de una suspensión de cultivo fresco de cada aislamiento. Luego se realizó una reacción de PCR para determinar la presencia de cada gen utilizando secuencias de primers y condiciones de reacción descriptas por varios autores: Konkel et al., 1999 (cadF), Hickey et al., 2011 (cdtA), Korsak et al., 2004 (iam), Muller et al., 2006 (flhA), and Bacon et al., 2000 (virB11), Datta et al., 2003 (flaA, cdtB, cdtC, ciaB, $\operatorname{racR})$.

Los resultados demostraron que de los 10 genes analizados, flaA, flhA, fueron detectados en todos los aislamientos evaluados. El tercer gen más prevalente fue cadF (91\%). Por otro lado, aproximadamente la mitad de los aislamientos fueron positivos para el cluster $c d t$ ( $c d t A, c d t B$ and $c d t C)$ (51\%). Para iam y racR las prevalencias fueron del $48 \%$ y $46 \%$ respectivamente, la prevalencia de ciaB fue de $32 \%$ y la de virB11 11\%.

Analizando los resultados teniendo en cuenta las especies de los aislamientos, para C. jejuni las prevalencias de los genes analizados fueron: $100 \%$ flaA y flhA, 93\% cadF, 65\% cdt, 64\% racR, 54\% ciaB, 29\% iam y $9 \%$ virB11. Para C.coli, en cambio, las prevalencias fueron: $100 \%$ flaA y flhA, 90\% cadF, 38\% cdt, 35\% racR, $8 \%$ ciaB, $82 \%$ iam y $17 \%$ virB11.

Si además de la especie del aislamiento se considera la información de la fuente de origen del mismo se pudo observar que los aislamientos de $C$. jejuni y $C$. coli provenientes de aves silvestres presentaron el mismo patrón de genes que los aislamientos de la misma especie obtenidos en pollos. La prevalencia del resto de los genes fue muy variable entre las diferentes fuentes de aislamientos. Solo una cepa aislada, obtenida a partir de mosca fue positiva a todos los genes de virulencia analizados.

De los resultados obtenidos encontramo que flaA, flhA, $c a d F$, genes relacionados a la expresión de adherencia y colonización de CT fueron encontrados con mayor frecuencia que el resto. La alta prevalencia de flaA y flhA, genes que codifican proteínas involucradas en la movilidad de CT indica el importante rol de los productos de estos genes en la virulencia de CT y revela una relación entre la movilidad y la virulencia (Wieczorek \& Osek 2008, Josefsen et al. 2015). El gen $c a d F$ tuvo una elevada prevalencia en aislamientos provenientes de pollos, lo que podría confirmar la importancia del producto de este gen en la colonización por CT del tracto gastrointestinal de estos animales (Wieczorek \& Osek 2008, Josefsen et al. 2015). Este estudio también mostró diferentes niveles de prevalencia de $r a c R$, gen que juega un rol en la colonización del ciego de los pollos por CT. Por otro lado más de la mitad de los aislamientos presentaron los tres genes del cluster $c d t$ los cuales son necesarios para la expresión de la citotoxina.

Se pudo observar también diferencias en la prevalencia de los genes $c d t$, racR, ciaB, iam según la especie del aislamiento. Esto podría demostrar diferencias genéticas que implican mecanismos distintos de colonización, adherencia y patogenicidad entre las especies de Campylobacter termotolerantes. Sumado a esto, el hecho de no encontrar diferencias en las prevalencias de los genes en ambas especies de Campylobacter termotolerantes aislados de distintas fuentes estaría indicando que la presencia de ciertos genes estaría relacionada con la especie del aislamiento y no de la fuente de origen.

La virulencia de las bacterias está condicionada por la expresión de genes de virulencia, por lo tanto, la presencia de estos genes determina la capacidad de los aislamientos de CT para adherirse e invadir las células 
(Wieczorek \& Osek 2008, Josefsen et al. 2015). Debe destacarse que la presencia de factores de virulencia particulares no es evidencia directa de la patogénesis. Sin embargo, sugiere fuertemente que pueden ser potencialmente capaces de producir la enfermedad (Wieczorek \& Osek 2008, Josefsen et al. 2015).

\section{Bibliografía}

Datta, S., Niwa, H., Itoh, K. (2003). Prevalence of 11 pathogenic genes of Campylobacter jejuni by PCR in strains isolated from humans, poultry meat and broiler and bovine faeces. J Med Microbiol, 52: 345-348.

Josefsen, M. H., Bhunia, A. K., Engvall, E. O., Fachmann, M. S., Hoorfar, J. (2015). Monitoring Campylobacter in the poultry production chain-From culture to genes and beyond. J Microbiol methods, 112: 118-125.

Silva, J., Leite, D., Fernandes, M., Mena, C., Gibbs, P. A., Teixeira, P. (2011). Campylobacter spp. as a foodborne pathogen: a review. Front Microbiol, 2: 200.

Wieczorek K., Osek J. (2008). Identification of virulence genes in Campylobacter jejuni and C. coli isolates by PCR. Bull Vet Inst Pulawy, 52(1): 211-216. 